
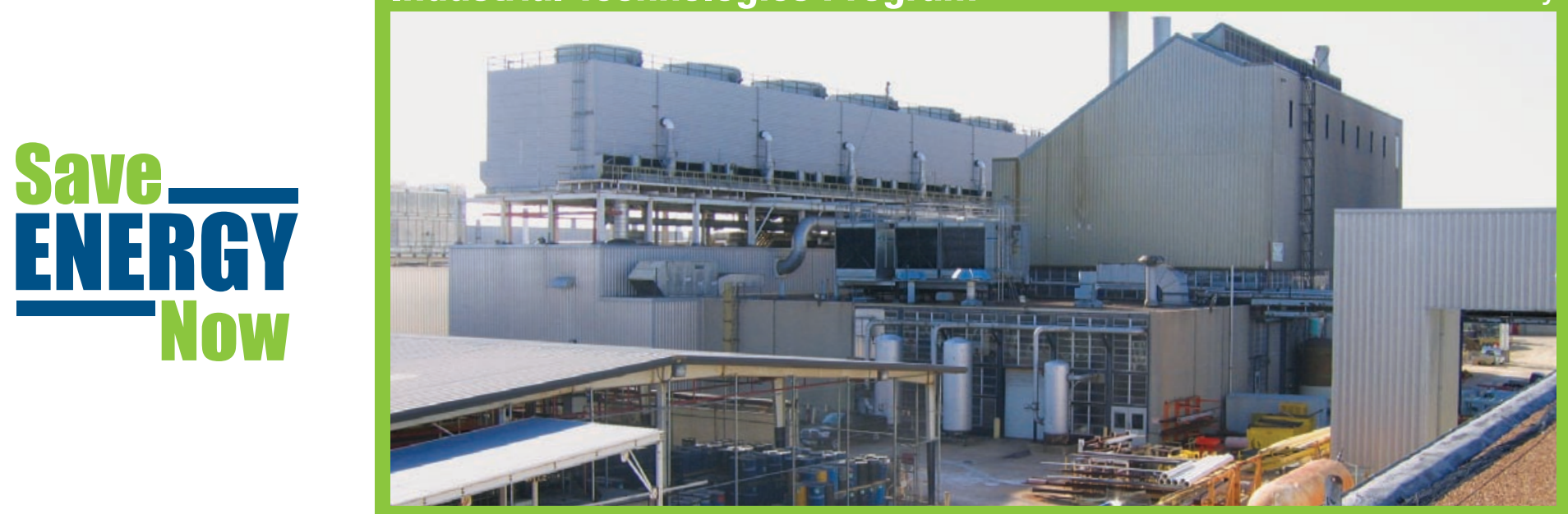

The powerhouse at Chrysler's St. Louis Assembly Complex provides steam, chilled water, and compressed air to both the north and south plants.

\title{
Chrysler: Save Energy Now Assessment Enables a Vehicle Assembly Complex to Achieve Significant Natural Gas Savings
}

\section{Benefits}

- Achieves annual energy savings of $\$ 627,000$

- Achieves annual natural gas savings of more than 70,000 MMBtu

- Yields a simple payback of just over 2 months

\section{Key Findings}

- Independent evaluations can provide "outside the box" solutions that achieve important energy savings.

- Although Chrysler had a strong energy management program, the Save Energy Now plant assessment helped identify new areas where energy savings could be captured.

- By optimizing boiler operation, improving boiler efficiency, and repairing failed steam traps, Chrysler achieved significant energy savings.

- The St. Louis complex's successful methodology is being replicated at other Chrysler facilities.

\section{Applications}

Steam systems are often found in large automobile plants, and they can be one of the biggest end-use energy consumers. Regular review of steam system performance and energy consumption can reveal malfunctions before these problems lead to wasted energy. This can yield significant energy savings and improvements in production.

\section{U.S. Department of Energy}

\section{Energy Efficiency and Renewable Energy}

Bringing you a prosperous future where energy is clean, abundant, reliable, and affordable

\section{Summary}

In July 2006, a Save Energy Now plant energy assessment was conducted for Chrysler at the company's truck and minivan assembly complex in St. Louis, Missouri. The main purpose of the assessment was to analyze the complex's steam system and identify opportunities for natural gas savings. In addition, the assessment was conducted to familiarize the complex's employees with the U.S. Department of Energy's (DOE) suite of steam system assessment tools and encourage them to use these tools consistently when evaluating their steam systems. DOE Energy Expert Riyaz Papar of Hudson Technologies conducted the assessment. It was successful in identifying some opportunities that enabled complex personnel to improve the steam system's efficiency and significantly reduce the complex's natural gas consumption.

The St. Louis complex's personnel began working to implement several assessment recommendations soon after it was completed. The first project involved optimizing boiler operation and implementing a load management strategy. They then reduced the flue gas oxygen content in one boiler, reduced boiler blowdown, and implemented an ongoing steam trap inspection and repair program. After applying these measures, the complex achieved total annual energy savings of more than 70,000 MMBtu and annual energy cost savings of around $\$ 627,000$. With total implementation costs of $\$ 125,000$, the simple payback was just over 2 months. Many other opportunities identified in the assessment are still under consideration, and the assessment methodology has been shared with several other Chrysler plants in the United States. 


\section{Project Drivers}

As part of Chrysler's energy management policy, independent evaluations are encouraged to provide fresh insights into potential energy efficiency opportunities. When a Save Energy Now analysis (based on the DOE Steam System Assessment Tool, or SSAT) uncovered innovative opportunities for energy efficiency in the steam system, the assessment team realized that these opportunities could enable them to meet corporate energy efficiency goals more quickly than they had anticipated. The company's Energy Champion worked closely with personnel in operations, maintenance, and its powerhouse to implement recommendations, and the complex's management provided full support to the Energy Champion to capture all economically justifiable opportunities.

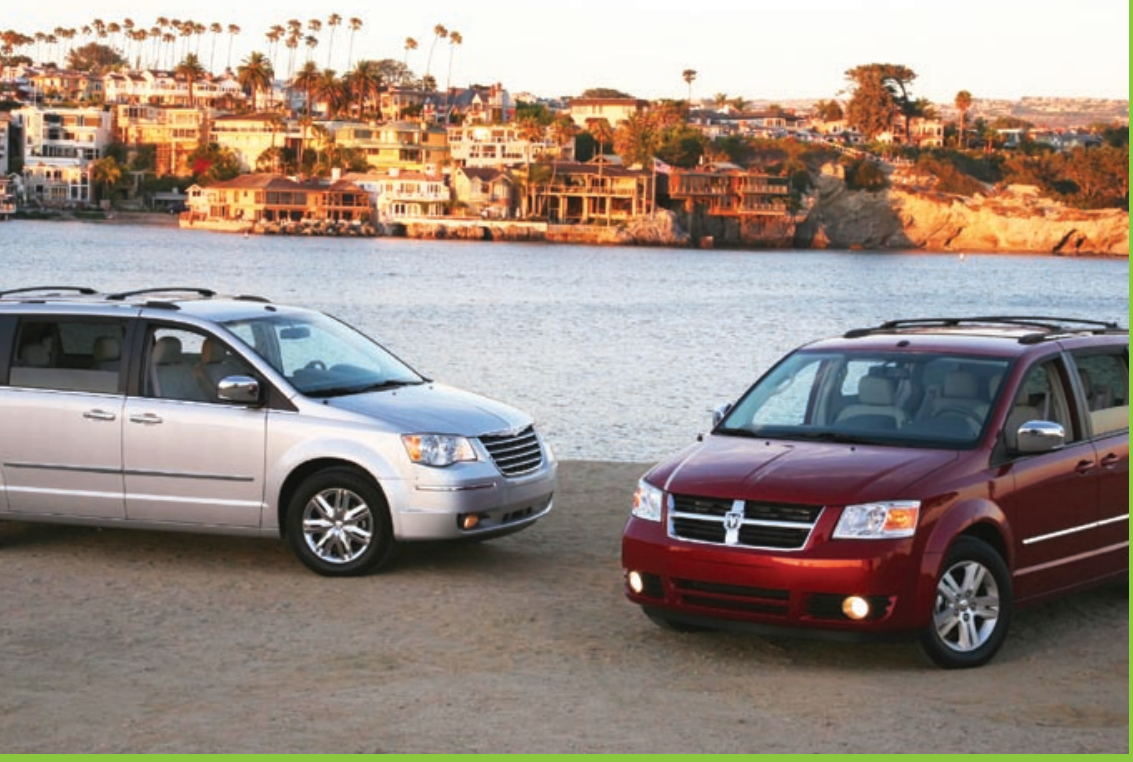

Minivans produced at Chrysler's St. Louis Assembly Complex south plant.

\section{"Thanks to the expertise of the Save Energy Now consultant, we have identified some new opportunities to build on our past progress, and we are moving quickly to implement those ideas."}

\section{Company and Plant Background}

Chrysler LLC produces many kinds of vehicles including passenger automobiles, trucks, minivans, and sport utility and commercial vehicles. Encompassing more than 5 million square feet, the St. Louis operation is divided into a north plant and a south plant. The north plant houses 2,300 workers and produces mainly cars and light duty trucks. With 3,200 employees, the south plant turns out Chrysler and Dodge minivans. Both plants receive their utilities (steam, chilled water, and compressed air) from the powerhouse, where four natural gas-fired water-tube boilers produce 140 psig saturated steam. Steam generation varies widely, depending on the season. Steam generation during summer (May to September) is typically $160,000 \mathrm{lb} / \mathrm{hr}$; average steam generation in spring, fall, and winter is $50,000 \mathrm{lb} / \mathrm{hr}$. During extremely cold weather, steam generation can be as high as $200,000 \mathrm{lb} / \mathrm{hr}$. The powerhouse also has three condensing steam turbine-driven chillers and 12 electric motor-driven chillers.

Steam is important for the St. Louis complex's production; it powers steam turbines and provides space and process heating. Because the St. Louis complex uses 2.4 million MMBtu of natural gas and landfill gas per year, energy costs account for a significant amount of the complex's total expenses. The company has set a target of a $2 \%$ annual reduction in energy use per unit of production. An employee designated as the "Energy Champion" defines corporate energy reduction goals and helps all the departments in each plant meet them.

\section{Assessment Overview}

The assessment at the St. Louis complex was sponsored by the DOE Industrial Technologies Program (ITP). The DOE Energy Expert who conducted the assessment is a qualified specialist in the use of DOE's Steam System Assessment Tool (SSAT) software and was able to provide an independent analysis of the steam system and instruction in the use of SSAT software. The Energy Expert formed an assessment team with two employees and trained 10 other Chrysler employees to use the SSAT. This allowed the employees to become familiar with the software, use it to analyze the efficiency of the St. Louis complex's steam system, and reproduce the analysis in other Chrysler facilities. 


\section{Assessment Recommendations}

Once the necessary data were collected, the assessment team used the SSAT to analyze the data and to identify a number of energy savings opportunities. Each opportunity was evaluated for technical and economic feasibility and classified according to near- and medium-term projects, depending on expected energy savings and associated payback periods.

\section{Near-term opportunities}

\section{- Optimize Boiler Operation and Load Manage-} ment Strategy - The load profile showed that three of the complex's four boilers were typically operated at less than $40 \%$ of full load capacity, while the fourth operated at between $50 \%$ and $60 \%$ of full load during summer months. This resulted in significant part-load losses and excessive energy consumption. The assessment showed that the complex's steam demand could be met by operating fewer boilers at close to full load capacity. Estimated annual energy and cost savings were 22,000 MMBtu and \$161,000.

- Raise Boiler Operating Pressure-During summer, three steam condensing turbines drive centrifugal chillers that help meet the complex's cooling load. The assessment team found that the steam turbines' thermal efficiency could be improved if the steam header pressure were raised from the complex's normal operating pressure, $140 \mathrm{psig}$, to $150 \mathrm{psig}$ in summer. Estimated annual energy savings were 5,400 MMBtu.

- Reduce Flue Gas Oxygen Level in Boiler \#1 - The assessment team found that boiler \#1 operated with an excess flue gas oxygen level of approximately $7 \%$. Since the optimal excess oxygen level should have been closer to $3.5 \%$, the excess level resulted in lost heat and greater fuel use. Powerhouse personnel examined the oxygen sensor and the oxygen trim controller and found that the sensor did not function properly. The assessment team estimated that reducing the excess oxygen level to $3.5 \%$ could result in annual energy and cost savings of 9,000 MMBtu and $\$ 68,000$.

- Reduce Boiler Blowdown - The assessment team found that boiler blowdown occurred too often during winter. During summer, when the condensate return was very high, powerhouse personnel managed blowdown well. However, as the weather grew colder and boiler loads declined, proper blowdown cycles were not maintained, especially on partly loaded boilers, resulting in an excessive blowdown rate. The assessment showed that installing new boiler blowdown controllers and improving protocols could reduce that rate. Estimated annual energy savings were approximately 3,000 MMBtu and $\$ 26,000$.

- Implement Blowdown Heat Recovery - The assessment team found that a heat exchanger was being used to recover heat from the blowdown stream. However, its configuration was causing some steam loss from the blowdown flash to ambient air. The team recommended reconfiguring the system by installing a blowdown flash tank upstream of the heat exchanger to capture steam and send it to the deaerator. The saturated hot water in the flash tank could then exchange heat with make-up water in the heat exchanger. Estimated energy savings were slightly less than 3,000 MMBtu.

\section{- Implement a Steam Trap Management Pro-} gram - The north plant's last steam trap audit was performed almost 10 years ago. Using the SSAT, analysts modeled the impact of a proactive steam trap management program that included annual steam trap testing, regular steam trap database updating, and replacing or repairing defective traps. The model estimated that implementing such a program could achieve annual energy and cost savings of 6,000 MMBtu and \$50,000.

\section{Medium-term opportunities}

- Enhance Feedwater Economizer on Boiler \#1 - In analyzing operating data, the assessment team noted that the temperature of the exiting flue gas from boiler \#1 was about $100^{\circ} \mathrm{F}$ higher than that from boiler \#4 at similar loads and feedwater temperatures, meaning that boiler \#1 was using more fuel. The team realized that this might be occurring because boiler \#4 was equipped with an enhanced fin-tube economizer, whereas boiler \#1 had a plain tube unit, or because the economizer on boiler \#1 was fouled. By cleaning or replacing the economizer on boiler \#1 with an enhanced fin-tube unit, the complex could save 11,520 MMBtu annually.

\section{- Replace Condensing Steam Turbines with Elec-} tric Motors-The assessment team found that the three condensing steam turbines that drove chillers provided excess chiller capacity. The turbines were operated at part load during summer under high demand conditions, along with several electrical chillers that were also not fully loaded. The team recommended either replacing the condensing steam turbines with electric motors or shutting one off and splitting the cooling load among the electrical chillers and the other two turbines. This installed capacity would meet the complex's cooling load. Although more electricity would be needed to meet that load, annual natural gas savings could be 135,000 MMBtu.

If implemented, the estimated net total annual energy cost savings that would result from these measures would be more than $\$ 900,000$.

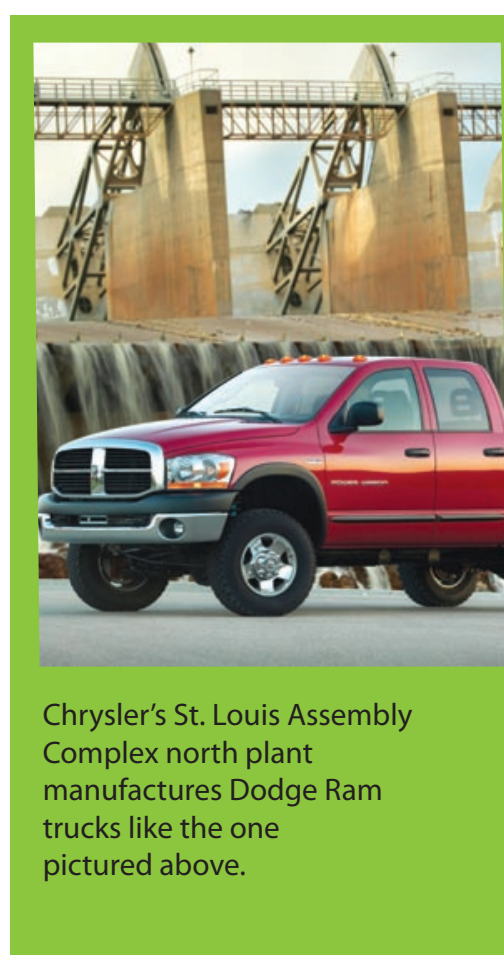




\section{Results}

The St. Louis complex's personnel realized that they could implement some of the recommendations in the assessment right away without affecting production. They began by optimizing boiler operation and starting a steam trap management program. They hired a contractor to train the powerhouse operators on a new boiler operating strategy that enabled them to shut down one boiler and operate the others closer to full load and design conditions. This yielded annual energy and cost savings of more than 48,000 MMBtu and $\$ 430,000$.

With total implementation costs of $\$ 125,000$ and annual energy cost savings of $\$ 627,000$, these achievements yield a simple payback of just over 2 months.

They then hired another outside expert to perform a steam trap audit in the north plant that found that 30 of the north plant's 48 steam traps had failed. Repairs on those traps were completed in fall 2007, yielding energy and cost savings of just under 10,000 MMBtu and $\$ 89,000$ per year. In addition, steam trap inspections and maintenance are being done more regularly.

Next, complex personnel replaced the oxygen sensor and probe in boiler \#1. The oxygen level is now in the proper range, and annual savings of approximately $9,400 \mathrm{MMBtu}$ and $\$ 84,000$ are being witnessed. To reduce boiler blowdown during the winter months, powerhouse personnel changed the blowdown protocols and installed automatic blowdown controllers. Annual energy and cost savings of 3,000 MMBtu and $\$ 24,000$ are resulting from this measure. The total annual energy savings from the implemented recommendations are more than 70,000 MMBtu. With total implementation costs of $\$ 125,000$ and annual energy cost savings of $\$ 627,000$, these achievements yield a simple payback of just over 2 months.

Some other recommendations had excessively lengthy payback periods or were too difficult to implement; e.g., replacing the three condensing steam turbines in the powerhouse would require a new main electrical line to the powerhouse and a new substation in addition to various land use issues.
The assessment's methodology and the use of the SSAT are being shared with other Chrysler facilities, such as those in Newark, New Jersey, and Sterling Heights, Michigan.

\section{Lessons Learned}

Opportunities to improve steam system efficiency can be found in multiple areas of a steam system and at various times of the year. Though employees at Chrysler's St. Louis assembly complex were familiar with the complex's steam system and its energy use patterns, an independent evaluation of the system using DOE's SSAT uncovered new opportunities outside the powerhouse with significant energy savings potential. By implementing several of the opportunities, complex personnel improved the steam system's performance and achieved important energy savings that enabled the complex's two plants to meet corporate goals for reducing energy use. In addition, the assessment's results encouraged management to apply its methodology at other facilities that use steam. DOE software tools such as SSAT and AIRMaster+, the Fan System Assessment Tool (FSAT), MotorMaster+, the Process Heating Assessment and Survey Tool (PHAST), the Pumping System Assessment Tool (PSAT), and 3E Plus ${ }^{\circledR}$ can be used to analyze industrial systems and processes and generate energy efficiency opportunities.

\section{Save Energy Now}

Save Energy Now is a national campaign started in 2005 in response to a rapid rise in energy prices. This campaign helps U.S. industry reduce energy use and supports national goals for energy security. Through Save Energy Now, DOE's Industrial Technologies Program (ITP) helps industrial plants operate more efficiently and profitably by identifying ways to reduce energy use in key industrial process systems. Visit www.eere.energy.gov/industry/ saveenergynow for more information.

\section{A Strong Energy Portfolio for a Strong America}

Energy efficiency and clean, renewable energy will mean a stronger economy, a cleaner environment, and greater energy independence for America. Working with a wide array of state, community, industry, and university partners, the U.S. Department of Energy's Office of Energy Efficiency and Renewable Energy invests in a diverse portfolio of energy technologies.

For more information, contact the EERE Information Center, 1-877-EERE-INF (1-877-337-3463), www.eere.energy.gov And visit the DOE Industrial Technologies Program home page: www. eere.energy.gov/industry 